\title{
冬季安徽菜子湖水位变化对主要湿地类型及冬候鸟生境的影响”
}

\author{
王晓媛,江 波**田志福,蔡金洲,林国俊 \\ (长江水资源保护科学研究所,武汉 430051)
}

\begin{abstract}
摘 要: “引江济淮” 工程调度运行后, 水位抬升将影响越冬候鸟适宜生境 (泥滩地和草本沼泽) 的出露, 并进而影响湿地 植物和底栖生物出露程度, 对越冬候鸟的栖息环境和食物可及性产生不利影响, 尤其是影响到挖掘啄取集团和浅水取食 集团的越冬水鸟. 基于安徽菜子湖不同水位对应的遥感影像解译结果, 分析了水位变化对菜子湖泥滩地和草本沼泽出露 的影响,并构建了菜子湖主要湿地类型的面积对水位响应的函数关系. 结果表明: 候鸟越冬期菜子湖泥滩地和草本沼泽 面积与水位均呈极显著负相关. 当水位到达 8.1 和 $8.6 \mathrm{~m}$ 时, 菜子湖将分别减少约 $16.8 \%$ 和 $10.0 \%$ 以及 $30.4 \%$ 和 $22.2 \%$ 的 泥滩地和草本沼泽. 1956-2015 年候鸟越冬期各月水位的变化趋势及水位大于 $8.1 \mathrm{~m}$ 的机率分析表明, 工程调度运行会 对菜子湖生态水文过程产生一定影响. 结果可为模拟不同水位对菜子湖主要湿地类型及面积的影响提供依据, 并从工程 的角度为菜子湖水位优化调度提供科学依据. 但由于数据缺乏, 未全面阐述湿地类型面积和生境的关系, 研究存在一定 的局限性. 建议加强菜子湖候鸟越冬期生境适应性调度研究及生态环境监测, 进一步掌握菜子湖越冬候鸟适宜生境及重 要越冬水鸟种群数量和分布格局对水位变化的响应,用科学实验和生态环境监测数据来加强菜子湖水位优化调度.
\end{abstract}

关键词: 菜子湖;湿地; 冬候鸟生境;水位变化

\section{Impact of water level changes in Lake Caizi (Anhui Province) on main wetland types and wintering bird habitat during wintering period}

\author{
WANG Xiaoyuan, JIANG Bo** , TIAN Zhifu, CAI Jinzhou \& LIN Guojun \\ (Changjiang Water Resources Protection Institute, Wuhan 430051, P.R.China)
}

\begin{abstract}
After the operation of the Yangtze-to-Huaihe Water Diversion Project, the water level rise will have certain submergence impact on the suitable wintering habitat for migratory birds (mudflats and herbaceous marshes), and adversely affect their habitat and food accessibility. Based on the interpretation results of remote sensing images corresponding to different water levels in Lake Caizi, this paper analyzes the effects of water level changes on the exposure of the mudflats and the herbaceous marshes in the Lake Caizi, and establishes the response function of the area of main wetland types to the water level changes. The results showed that there was a significant negative correlation between the habitat area of mudflats and herbaceous marshes and water level during the overwintering period. The area of mudflats and herbaceous marshes was 6057.6 ha and 4460.9 ha respectively at current water level of $6.97 \mathrm{~m}$. When the water level rises to $7.5 \mathrm{~m}$, it will lose about $13.7 \%$ of mudflats and $5.5 \%$ of herbaceous marsh habitats. When the water level rises to $8.1 \mathrm{~m}$, it will lose about $16.8 \%$ of mudflats and $10.0 \%$ of herbaceous marsh habitats. When the water level rises to $8.6 \mathrm{~m}$, it will lose about $30.4 \%$ of mudflats and $22.2 \%$ of herbaceous marsh habitats. From 1956 to 2015 , the trend of water level and the probability of water level exceeding $8.1 \mathrm{~m}$ during the overwintering period of migratory birds both indicate that the engineering dispatching operation will have certain influence on the ecological hydrological process of the Lake Caizi. This paper on the one hand provides the basis for simulating the effects of different water levels on the area of main wetland types in Lake Caizi. On the other hand, it provides the scientific basis for the water level optimization of the Lake Caizi from the engineering perspective. However, due to the lack of data, this article has some limitations in fully explaining the relationship between the area of wetland types and habitat. It is suggested to implement experimental study on habitat adaptation and ecological environment monitoring during the overwintering period of migratory birds to further understand the response of suitable habitat, and important wintering
\end{abstract}

* 国家重点基础研发计划项目 (2017YFC0405303) 和水利部预算项目 (H017001, H017002) 联合资助. 2018-03-09 收稿;2018-04-18 收修改稿. 王晓媛(1978 ), 女, 硕士, 高级工程师;E-mail:sunnywxy@ 163.com.

** 通信作者; E-mail :jbshuibao415@126.com. 
bird population and distribution pattern to water level changes.

Keywords: Lake Caizi; wetland; wintering bird habitat; water level change

菜子湖湿地是典型的长江中下游浅水通江湖泊湿地, 孕育着丰富的生物资源, 是白头鹤、东方白鹳、小 天鹅、白额雁、白琵路、豆雁、鸿雁等重要水鸟的越冬栖息地, 对生态系统和生物多样性保护具有重要意义. 鉴于菜子湖在越冬水鸟保护的重要地位, 安徽大学和安庆市林业局从 2004 年开始对菜子湖越冬水鸟和植 被开展调查, 为菜子湖湿地生物多样性保护提供了基础数据 ${ }^{[1-3]}$. 根据历年监测数据, 菜子湖越冬水鸟种类 和数量总体上较为稳定, 基本维持在种类 30 40 种和数量 20000 只以上的水平. 菜子湖区分布有国家重点 保护水鸟 10 种, 其中国家 I 级重点保护水鸟 4 种: 白头鹤、白鹤、东方白鹳、黑鹳; 国家 II 级重点保护水鸟 6 种: 白额雁、鹗蓄、灰鹤、小天鹅、白琵路和白枕鹤, 主要分布在湖区较宽阔的水域及湖岸滩涂. 根据国际重要 湿地鸟类种群标准, 鸿雁、豆雁、东方白鹳、白琵鹭、白头鹤、白鹤和大白鹭 7 种水鸟已经达到国际重要湿地 标准.

候鸟越冬期菜子湖泥滩地和草本沼泽出露, 尤其是滩涂湿生植被得以发育 (优势种为陌上菅 (Carex thunbergii), 主要伴生种有肉根毛茛 (Ranunculus polii) 和朝天委陵菜 (Potentilla supina)), 为越冬水鸟提供重 要的栖息地和受食地 ${ }^{[4-6]}$. 水位动态变化是影响菜子湖湿地生态水文过程的关键因素之一, 候鸟越冬期菜子 湖泥滩地和草本沼泽出露与水位变化密切相关 ${ }^{[7]}$. 候鸟越冬期水位长期维持在较高水平, 将不利于陌上菅、 肉根毛莨和朝天委陵菜等湿生植被的生长和发育. 主要湿地类型的变化和滩涂湿生植被的消失将对冬候鸟 生境 (包括栖息生境和受食生境) 产生一定不利影响 ${ }^{[4-6]}$. 因此,定量化分析候鸟越冬期菜子湖主要湿地类型 的面积对水位的动态响应, 有利于揭示越冬候鸟适宜生境随水位变化的动态变化规律, 为菜子湖水位科学 调度提供重要依据.

“引江济淮”工程是综合性战略水资源配置工程. 菜子湖是双线引江布局的主力线路, 承担 $60 \%$ 的总引 江水量和 $85 \%$ 以上的自流引江任务, 是重要引江口门和巢湖第二通江航道, 对保障工程安全运行和维护工 程效益意义重大. “引江济淮” 工程运行后, 规划水平年 2030 、2040 年菜子湖候鸟越冬期水位分别按 7.5 和 $8.1 \mathrm{~m}$ 控制 (黄海基面), 较现状水位有一定抬升,一定程度上将影响越冬候鸟适宜生境 (泥滩地和草本沼 泽) 的出露, 并对越冬候鸟的栖息环境和食物可及性产生不利影响, 尤其是影响到挖掘豚取集团和浅水取食 集团的越冬水鸟. 根据菜子湖水位变化特征分析, “引江济淮”工程实施对菜子湖水位的抬升影响主要在 12 月一次年 3 月,与冬候鸟的越冬期基本重叠. 水位抬升将直接影响菜子湖越冬候鸟适宜生境的面积及湿地植 物和底栖生物出露程度, 从而影响越冬水鸟食物资源、种群的空间分布和群落组成. 工程实施后菜子湖候鸟 越冬期水位上升, 泥滩地和草本沼泽湿地面积减少, 将减少部分冬候鸟的适宜生境, 冬候鸟生境的组成结构 也发生相应变化,影响食物资源的时空变化及食物资源可利用性,对区域内冬候鸟的栖息和受食产生不利 影响. 目前, 国内外关于湖泊水位调度对湿地生境、水鸟种群数量及空间分布格局、群落结构和取食集团结 构等综合性影响的研究和深度剖析相对较少. 而且由于每个湖泊气候、水文、地形条件及不同越冬候鸟生活 习性的独特性和差异性,已有研究成果很难进行大范围的推广. 在长江大保护的政策背景下, 工程前期设计 阶段,多家设计单位就菜子湖水位的调度方案进行了数次论证, 但如何优化水位调控对策, 协调工程效益和 生态大保护之间的关系,仍是“引江济淮”这项大型跨流域调水工程的重大难点.

本文基于菜子湖不同水位对应的遥感影像解译结果, 分析了水位变化对菜子湖泥滩地和草本沼泽出露 的影响, 并构建了菜子湖主要湿地类型的面积对水位响应的函数关系, 结果可为模拟不同水位对菜子湖主 要湿地类型及面积的影响提供依据, 并从工程的角度为菜子湖水位优化调度提供科学依据. 对 $1956-2015$ 年候鸟越冬期 (12 月一次年 3 月) 各月水位的变化趋势及水位大于 $8.1 \mathrm{~m}$ 的机率进行分析,能定量揭示工程 调度运行可能会对菜子湖生态水文过程产生的影响, 为协调 “引江济淮” 工程效益和菜子湖生态保护提供重 要支撑.

\section{1 研究区概况}

菜子湖包括嬉子湖、白兔湖和菜子湖, $1950 \mathrm{~s}$ 末湖泊总面积 $300 \mathrm{~km}^{2}$. 由于沿湖周围怎, 现湖泊水面面积 


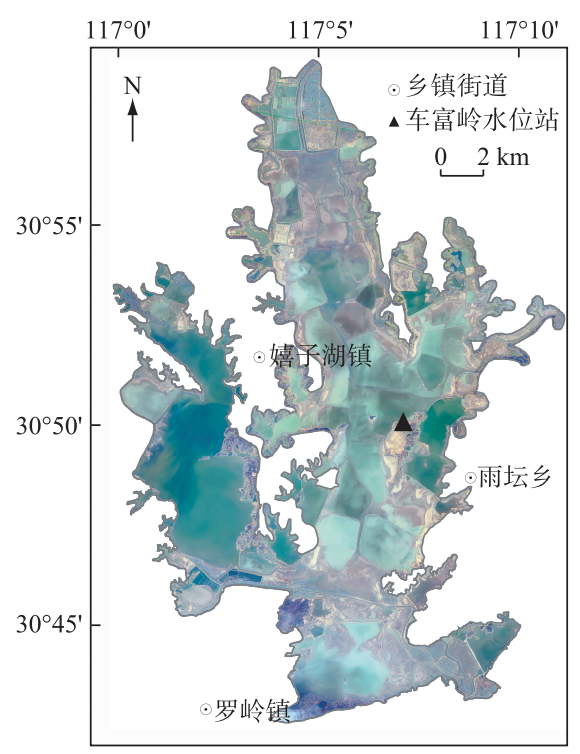

图 1 研究区域卫星影像图

Fig.1 Satellite image of the study area

为 $242.9 \mathrm{~km}^{2}$ (相应水位 $15.1 \mathrm{~m}$ ), 总容积为 16.1 亿 $\mathrm{m}^{3}$. 菜子 湖流域来水经菜子湖调蓄后由长河水道汇人长江, 该湖原 与长江天然沟通, 1959 年建成枞阳闸后开始成为水库型湖 泊. 建闸前, 菜子湖水位涨落与长江水位基本一致; 建闸后, 流域来水排泄人江和引江由枞阳闸控制. 菜子湖周边供水 任务轻、防汛任务重, 菜子湖水位实际调度过程中非汛期不 需要维持高水位以增加蓄水量. 根据菜子湖枞阳闸控制运 用办法, 现状汛期蓄水位分月控制: 6 月为 $8.6 \sim 9.1 \mathrm{~m}, 7 、 8$ 月为 $9.1 \sim 9.6 \mathrm{~m}$. 干早年份抗旱需要湖泊蓄水位控制在 10.6 $\mathrm{m}$ 以内. 水位人为调控和调度过程维持了菜子湖丰水期水 位上涨,枯水期滩涂出露的湿地变化节律. 湖区水位在 7、8 月份最高, 9 月份湖区水位开始逐渐下降, 3 月份水位逐渐 上升. 根据菜子湖湖区车富岭水位站 $\left(30^{\circ} 50^{\prime} 0.6^{\prime \prime} \mathrm{N}, 117^{\circ} 6^{\prime}\right.$ $53^{\prime \prime} \mathrm{E}$ ) 多年水位观测数据, 建闸后菜子湖历年最高水位为 $15.06 \mathrm{~m}$,最低水位为 $6.46 \mathrm{~m}$.

菜子湖位于中国候鸟三大迁徙线路中线和全球候鸟主 要迁徙通道之一的东亚一澳大利亚水鸟迁徙通道上, 是豆雁 和小天鹅等候鸟在东亚迁徙路线上的重要越冬地和停歇地 之一, 也是全球受胁物种白头鹤、东方白鹳等在东亚地区的 越冬地之一. 每年 10-11 月越冬候鸟陆续到达, 12 月一次年 1 月菜子湖越冬候鸟数量达到峰值, 次年 3 月候 鸟陆续北迁, 4 月中下旬全部离开. 候鸟越冬期菜子湖湿地出露与水位变化密切相关, 10 月一次年 1 月菜子 湖水位逐渐下降 $(9.40 \sim 6.87 \mathrm{~m})$, 泥滩地和浅水沼泽出露面积逐渐增大; 次年 3 月菜子湖水位逐渐上升 $(7.08$ $\mathrm{m})$, 泥滩和浅水沼泽面积逐渐缩小, 湖泊水域面积逐渐增加. 研究区域示意图见图 1.

\section{2 数据与研究方法}

“引江济淮”工程引江调度方式为优先利用西兆河线路引江, 减轻菜子湖抬升压力. 规划水平年 2030 年, 菜子湖候鸟越冬期水位按 $7.5 \mathrm{~m}$ 控制; 规划水平年 2040 年, 菜子湖候鸟越冬期水位按 $8.1 \mathrm{~m}$ 控制. 根据 菜子湖车富岭水位站 1956- 2015 年实测资料, 菜子湖多年平均湖水位为 $8.53 \mathrm{~m}$, 候鸟越冬期 (12 月一次年 3 月)多年平均水位 $6.98 \mathrm{~m}$, 菜子湖历年逐月平均水位见图 2a. “引江济淮” 工程建成运行对菜子湖水位的影 响主要集中在候鸟越冬期. 规划水平年 2030 和 2040 年,多年平均情况下, 菜子湖候鸟越冬期 ( 12 月一次年 3 月) 水位由现状的 $6.98 \mathrm{~m}$ 分别增加到 7.5 和 $8.1 \mathrm{~m}$, 分别增加 0.52 和 $1.12 \mathrm{~m}$ (图 $2 \mathrm{~b}$ ).

菜子湖 1 月多年平均水位为 $6.87 \mathrm{~m}$, 该时段越冬候鸟数量达到峰值, 越冬候鸟适宜生境面积最大. 以菜 子湖水域 (包括嬉子湖、菜子湖、白兔湖) 为界, 根据研究区域可获取的卫星影像对应的日期和车富岭水位站 历史水位数据对应的日期对影像数据和水位数据进行匹配. 研究区域可获取的卫星影像中, 分别有 1 个时 期的高分卫星影像数据对应的菜子湖车富岭水位站实测水位为 6.97 和 $7.05 \mathrm{~m}$, 与多年平均水位 $6.87 \mathrm{~m}$ 接 近, 选取这 2 期遥感影像数据. 研究区域可获取的卫星影像中, 分别有 1 个时期的卫星影像数据对应的菜子 湖车富岭实测水位数据与工程调度运行水位 7.5 8.1 及 $8.6 \mathrm{~m}$ 接近, 分别选取这些遥感影像进行解译, 分析 菜子湖候鸟越冬期工程调度运行对主要湿地类型面积及空间分布的影响及主要湿地类型面积对水位变化 的动态响应. 结合长时间序列水位数据, 分析候鸟越冬期各月水位的变化趋势及水位大于 8.1 和 $8.6 \mathrm{~m}$ 的出 现机率,定量化揭示工程调度运行对菜子湖生态水文过程的影响, 为水位的优化调控提供依据.

\section{1 遥感影像節选与解译}

本文使用的遥感影像为 Landsat5 TM 及高分一号卫星遥感影像. 其中高分一号卫星遥感影像为 $2 \mathrm{~m}$ 全 色 $/ 8 \mathrm{~m}$ 多光谱融合遥感影像 (融合后分辨率 $2 \mathrm{~m}$ ), Landsat5 TM 卫星遥感影像地面精度为 $30 \mathrm{~m}$, 轨道编号为 121/039. 影像选择主要考虑三方面的因素: 1) 遥感影像质量, 选取天气晴朗, 无云或少云, 无色差的影像. 

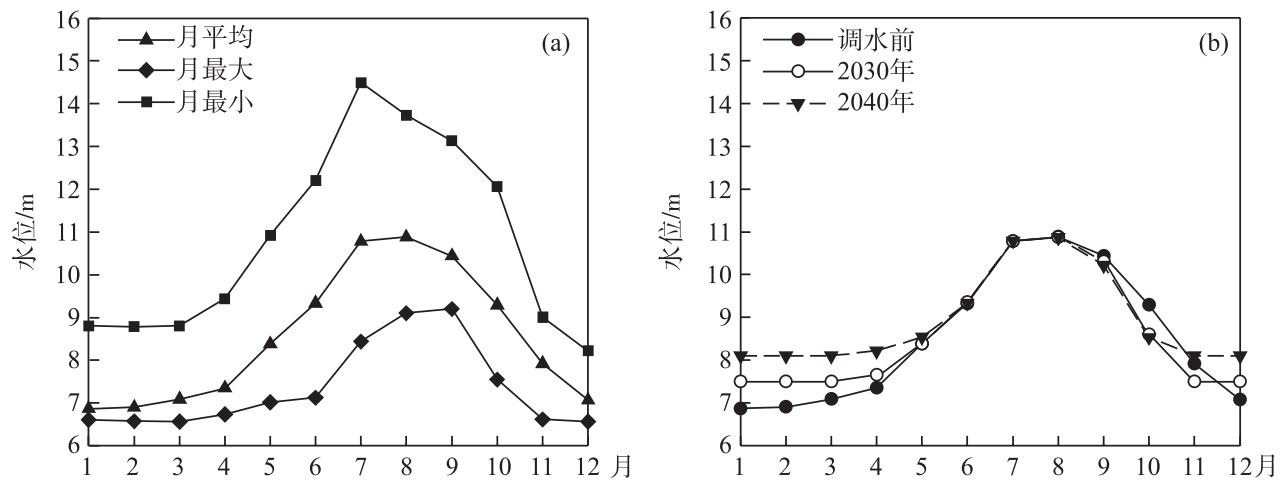

图 2 菜子湖多年逐月平均水位 (a) 及“引江济淮”工程调度运行对水位的影响

Fig.2 Multi-year monthly average water level of Lake Caizi and the influence of the operation of the Yangtze-to-Huaihe Water Diversion Project on the water level

2)篮选的影像能反应水位变幅. 3 ) 筛选的影像尽量集中在枯水期. 根据以上原则,共篮选 5 景遥感影像 (表 1). 研究区域的土地覆被类型包括水域、草本沼泽、泥滩地、林地、水稻田、建设用地, 根据每种土地类型特有 的光谱特征, 并结合定点调查, 利用 ERDAS 软件对遥感影像进行分类. 对每景遥感影像的解译结果, 通过误 差矩阵 (Error Matrix) 的 Kappa 系数进行总体精度 (Overall Accuracy) 验证, 并去除碎点后统计各土地覆被类 型的面积. 鉴于 Landsat5 TM 数据空间分辨率较粗, 在采用该数据进行湿地面积和水位的分析时, 会对结果 的精确性产生一定影响, 因此在进行解译时对 $7.54 \mathrm{~m}$ 以下水位的解译结果, 以高分一号的数据解译结果为 准. 同时, 结合实地调查数据和局部区域的地形测量数据, 对 Landsat5 TM 的解译结果进行优化, 减少其解译 误差.

表 1 菜子湖遥感影像耖选及对应水位情况

Tab.1 Remote sensing image screening and corresponding water level of Lake Caizi

\begin{tabular}{ccccc}
\hline 日期 & 影像 & 产品类型 & 水位 $/ \mathrm{m}$ & 解译水位 $/ \mathrm{m}$ \\
\hline $2015-01-22$ & 高分一号 & $2 \mathrm{~m}$ 全色 $/ 8 \mathrm{~m}$ 多光谱 & 6.97 & 6.97 \\
$2013-12-29$ & 高分一号 & $2 \mathrm{~m}$ 全色 $/ 8 \mathrm{~m}$ 多光谱 & 7.05 & - \\
$2015-12-16$ & 高分一号 & $2 \mathrm{~m}$ 全色 $/ 8 \mathrm{~m}$ 多光谱 & 7.54 & 7.50 \\
$2009-05-03$ & Landsat TM & $30 \mathrm{~m}$ 多光谱 & 8.08 & 8.10 \\
$2009-11-03$ & Landsat TM & $30 \mathrm{~m}$ 多光谱 & 8.60 & 8.60 \\
\hline
\end{tabular}

\section{2 菜子湖主要湿地类型对水位变化的动态响应}

为量化菜子湖主要湿地类型对水位变化的动态响应关系, 根据不同水位对应的主要湿地类型的面积, 采用 SPSS 16.0 软件的曲线估计 (Curve Estimation) 功能, 以水位作为自变量、主要湿地类型(水域、草本沼 泽、泥滩地) 的面积作为因变量, 分别拟合各湿地类型面积与水位的回归关系, 并篮选出拟合度最好且具有 生态学意义的回归模型.

\section{3 长时间序列水位数据分析}

水位动态变化是影响菜子湖湿地结构和过程的关键因素. 采用 Mann-Kendall 趋势检验法对 1956- 2015 年候鸟越冬期 (12 月一次年 3 月) 长时间序列水位数据进行趋势性分析. Mann-Kendall 趋势检验法 ${ }^{[8-9]}$, 是一种 非参数检验方法, 该方法不需要假定数据的分布形式、对奇异值和缺失值也不敏感, 被广泛应用于水文数据单 调变化趋势分析 ${ }^{[10]}$. 该方法能定量化反映长时间序列水位的变化趋势及未来进一步增加的幅度, 揭示工程调 度运行对水位变化趋势的影响. 在水位变化趋势的基础上,统计候鸟越冬期历史水位(1956- 2015 年)大于 8.1 $\mathrm{m}$ 的出现机率, 以揭示工程调度运行后水位长期维持在 $8.1 \mathrm{~m}$ 对菜子湖生态水文过程的影响. 


\section{3 结果与分析}

\section{1 水位变化对湿地类型与面积的影响}

根据解译结果 (图 3), $6.97 \mathrm{~m}$ 水位时, 水域面积为 $11497.0 \mathrm{hm}^{2}$, 泥滩地面积为 $6057.6 \mathrm{hm}^{2}$, 草本沼泽面 积为 $4460.9 \mathrm{hm}^{2}$, 水稻田面积为 $1851.2 \mathrm{hm}^{2} ; 7.5 \mathrm{~m}$ 水位时, 水域面积为 $12591.8 \mathrm{hm}^{2}$, 泥滩地面积为 5229.5 $\mathrm{hm}^{2}$, 草本沼泽面积为 $4214.6 \mathrm{hm}^{2}$, 水稻田面积为 $1838.4 \mathrm{hm}^{2} ; 8.1 \mathrm{~m}$ 水位时, 水域面积为 $13012.8 \mathrm{hm}^{2}$, 泥滩地 面积为 $5039.0 \mathrm{hm}^{2}$, 草本沼泽面积为 $4013.5 \mathrm{hm}^{2}$, 水稻田面积为 $1816.4 \mathrm{hm}^{2} ; 8.6 \mathrm{~m}$ 水位时, 水域面积为 $14432.7 \mathrm{hm}^{2}$, 泥滩地面积为 $4218.3 \mathrm{hm}^{2}$, 草本沼泽面积为 $3469.1 \mathrm{hm}^{2}$, 水稻田面积为 $1778.7 \mathrm{hm}^{2}$.

候鸟越冬期菜子湖水位上升引起泥滩湿地和草本沼泽湿地出露面积减少, 水域面积增加. 相较于 6.97 $\mathrm{m}$ 水位, 候鸟越冬期水位上升到 $7.5 \mathrm{~m}$ 时, 泥滩地出露面积减少 $828.1 \mathrm{hm}^{2}$, 减幅 $13.7 \%$, 草本沼泽出露面积减 少 $246.3 \mathrm{hm}^{2}$, 减幅 $5.5 \%$. 水位从 $7.5 \mathrm{~m}$ 进一步上升到 $8.1 \mathrm{~m}$ 时, 相较于 $6.97 \mathrm{~m}$ 水位, 泥滩地出露面积减少 $1018.6 \mathrm{hm}^{2}$, 减幅 $16.8 \%$, 草本沼泽出露面积减少 $447.4 \mathrm{hm}^{2}$, 减幅 $10.0 \%$. 水位从 $8.1 \mathrm{~m}$ 进一步上升到 $8.6 \mathrm{~m}$ 时, 相较于 $6.97 \mathrm{~m}$ 水位, 泥滩地出露面积减少 $1839.3 \mathrm{hm}^{2}$, 减幅 $30.4 \%$, 草本沼泽出露面积减少 $991.8 \mathrm{hm}^{2}$, 减 幅 $22.2 \%$ (表 2 ).

表 2 水位变化对湿地类型与面积的影响

Tab.2 Influence of water level change on wetland types and areas

\begin{tabular}{|c|c|c|c|c|c|c|}
\hline \multirow{2}{*}{ 湿地类型 } & \multicolumn{3}{|c|}{ 面积变化/hm² } & \multicolumn{3}{|c|}{ 面积占比变化/\% } \\
\hline & $6.97 \sim 7.50 \mathrm{~m}$ & $6.97 \sim 8.10 \mathrm{~m}$ & $6.97 \sim 8.60 \mathrm{~m}$ & $6.97 \sim 7.50 \mathrm{~m}$ & $6.97 \sim 8.10 \mathrm{~m}$ & $6.97 \sim 8.60 \mathrm{~m}$ \\
\hline 水域 & 1094.8 & 1515.9 & 2935.7 & 9.5 & 13.2 & 25.5 \\
\hline 草本沼泽 & -246.3 & -447.4 & -991.8 & -5.5 & -10.0 & -22.2 \\
\hline 泥滩地 & -828.1 & -1018.6 & -1839.3 & -13.7 & -16.8 & -30.4 \\
\hline 水稻田 & -12.8 & -34.7 & -72.4 & -0.7 & -1.9 & -3.9 \\
\hline
\end{tabular}

\section{2 湿地类型对水位变化的动态响应}

曲线估计结果表明,水位变化对水域、泥滩地和草本沼泽面积解释能力最强的均为二次方程. 3 种湿地 类型与水位之间具有极显著 $(P<0.01)$ 或显著 $(P<0.05)$ 的关系, 且回归方程的决定系数 $\left(R^{2}\right)$ 均在 0.97 以上 (图 4). 候鸟越冬期湿地出露与水位变化密切相关, 水位变化将引起菜子湖泥滩地和草本沼泽湿地出露面 积的变化.

\section{3 长时间系列水位动态变化}

趋势分析结果表明, 12 月一次年 3 月 (1956-2015 年) 的水位均表现为显著或极显著增加趋势 (图 5), $Z$ 值分别为 $5.96(P<0.01) 、 3.84(P<0.01) 、 3.06(P<0.01)$ 和 $2.31(P<0.05)$, 但近 60 年水位总体抬升仅 $0.28 \sim$ $0.36 \mathrm{~m}$. 按此趋势对菜子湖 2030 和 2040 年进行预测, 水位相比现状将仅抬升不到 0.08 和 $0.12 \mathrm{~m}$.

菜子湖越冬候鸟期各月长系列 (1956-2015 年) 水位大于 $8.1 \mathrm{~m}$ 的机率均较低, 总体上也仅是 1959 、 $1973 、 1978-1979$ 和 1985 年 4 个年份的局部时段出现了水位大于 $8.1 \mathrm{~m}$ 的情况,近 30 年未出现水位大于 $8.1 \mathrm{~m}$ 的情况 (表 3 ). 候鸟越冬期菜子湖水位长期维持在 $8.1 \mathrm{~m}$ 以上将会影响候鸟越冬期菜子湖湿地的生态 水文过程.

\section{4 讨论}

水位过程变化是影响候鸟越冬的重要因素 ${ }^{[11]}$. 近年来, 国内学者针对水位变化对湿地生态系统结 构 ${ }^{[4,12]}$ 、湿地水文过程 ${ }^{[13]}$ 、湿地生态环境 ${ }^{[14]}$ 、越冬季候鸟栖息地 ${ }^{[4-6,15-16]}$ 的影响等展开了相应研究, 为研究水 位变化对湿地生态水文过程和越冬候鸟生境的影响提供了理论思路. 齐述华等 ${ }^{[4]}$ 根据多年越冬候鸟野外调 查资料, 在分析主要越冬候鸟习性和生境偏好的基础上, 通过对具有不同水位的鄱阳湖湿地卫星遥感影像 进行生境类型分类,利用景观指数定量分析不同水位下鄱阳湖湿地越冬候鸟的生境类型和空间分布结构. 夏少霞等 ${ }^{[6]}$ 运用 RS 和 GIS 技术, 确定了典型年份以及特征水位下候鸟栖息地的面积, 同时利用统计方法, 

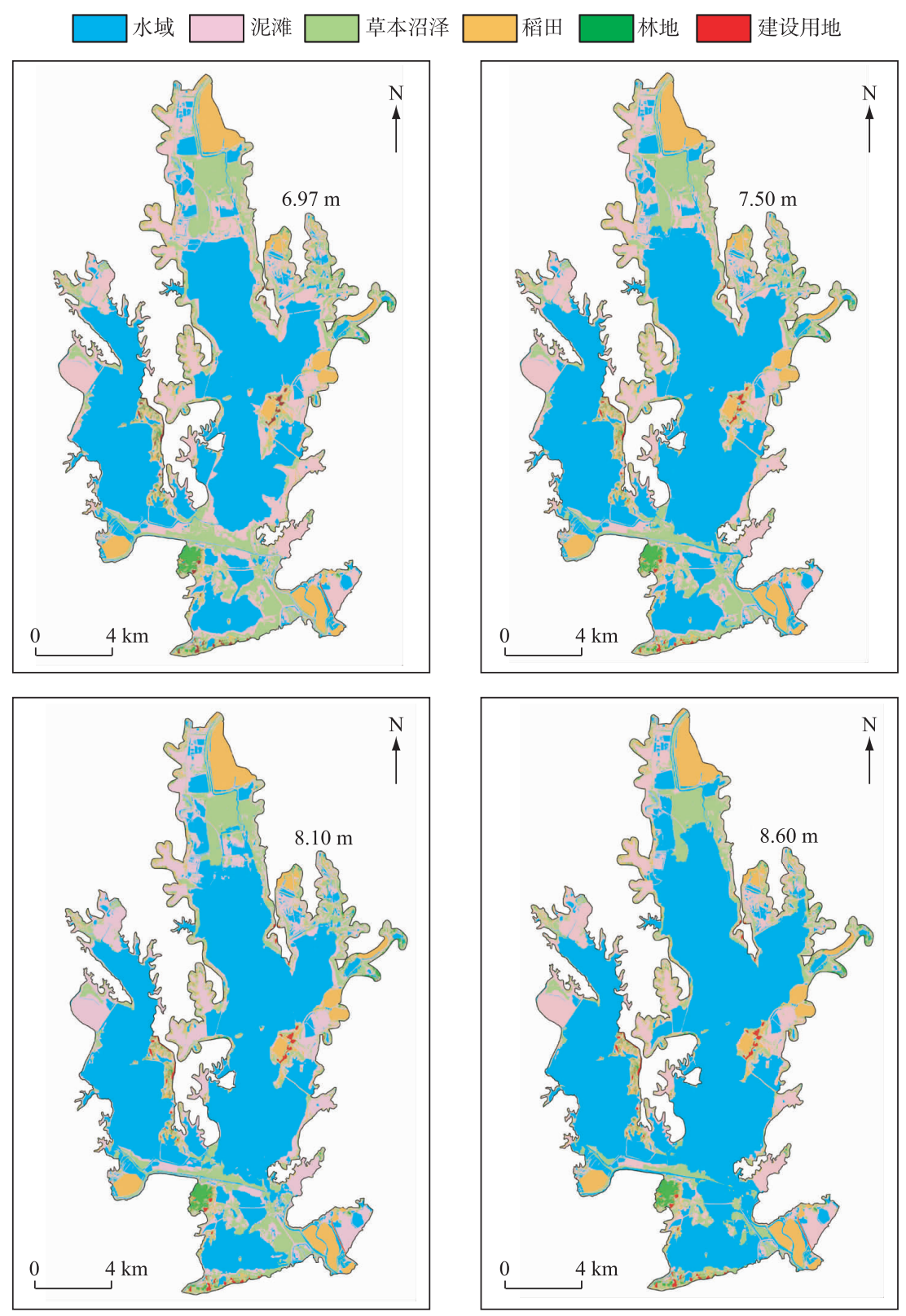

图 3 不同水位对应的湿地类型及其分布

Fig.3 Wetland types and its spatial distribution in relation to different water levels

分析了栖息地面积及其内部结构与水位之间的关系,并从湿地与候鸟保护的角度,评估了拟建鄱阳湖水利 枢纽工程的水位调度方案对候鸟栖息地可能的影响. 刘成林等 ${ }^{[11]}$ 选择不同水位的遥感影像资料, 经解译定 量分析不同水位过渡带面积及其空间分布, 从而分析不同水位条件对候鸟栖息地的影响,进而分析研究鄱 阳湖国家级自然保护区微地形过程候鸟栖息地变化及对候鸟越冬的影响. 胡振鹏等 ${ }^{[12]}$ 利用 $3 \mathrm{~S}$ 技术对鄱阳 湖湿地进行了分类, 研究了各种类型湿地植物生态系统的生境、主要植物群落结构和分布规律. 胡振鹏 ${ }^{[15]}$ 从保护区地形地貌和气象水文特征出发, 研究了鄱阳湖国家级自然保护区的湿地植物生态系统的结构和白 鹤越冬期的生境与取食情况,及白鹤越冬对鄱阳湖水位变化的响应.上述研究结果均表明: 水位升高会造成 

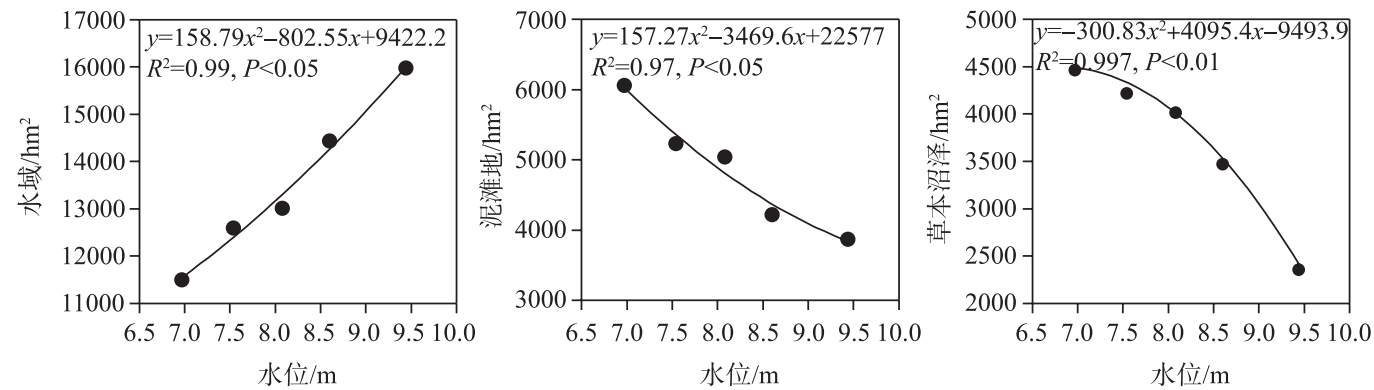

图 4 主要湿地类型对水位变化的动态响应

Fig.4 Dynamic response of main wetland types to water level change
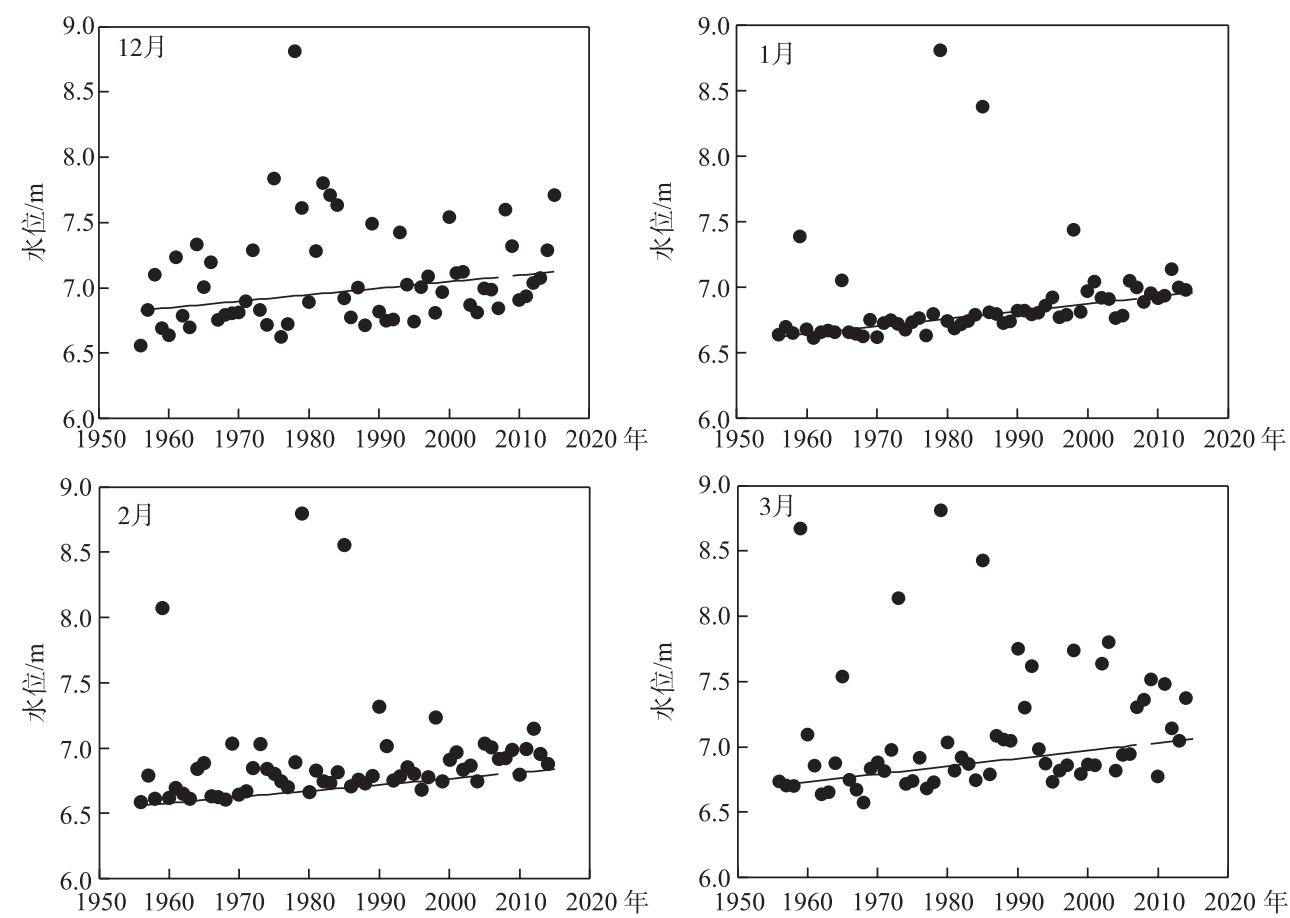

图 512 月一次年 3 月水位趋势分析

Fig.5 Trend analysis of water level from December to March in next year

冬候鸟栖息地面积减少, 当水位超过一定的范围时, 将可能无法维持现有冬候鸟的栖息需求. 相比以往研 究,本文从工程调度的角度出发,系统地将水位变化一湿地动态一鸟类栖息地关联. 以水位变化与湿地类型 出露面积关系为核心, 选取 $6.97 \mathrm{~m}$ 水位对应的遥感影像结果作为湿地现状出露情况,结合 “引江济淮”工程 调度特点, 分别选取 7.5、8.1 和 $8.6 \mathrm{~m}$ 水位对应的遥感影像进行解译, 定量化分析水利过程一水位变化一湿地 类型的相互关系,并在此基础上探讨湿地类型变化对冬候鸟栖息地和候鸟种群数量的影响.

菜子湖区不同的鸟类占据不同的生态位. 水位、水域面积比例、草洲植被盖度、食物资源丰富度等是影 响菜子湖水鸟分布的主要环境因子. 冬季在水较深的湖区分布有鸭类和小天鹅等游禽,浅水区域则分布有 鹤类和鹳类等涉禽, 植食性鸟类主要分布在湖周植被较丰富的地区. 菜子湖分布的几种国家重点保护水鸟 对湖周泥滩地、草本沼泽和浅水水域的依赖性均较强. 随着菜子湖沉水植物如苦草等分布面积缩小和食物 可利用资源的减少,水稻田成为白头鹤重要受食地之一, 白头鹤种群主要分布在团结大圩、双兴、先让村等 
区域. 菜子湖是白鹤迁徙过程中重要的停歇地和受 食地. 菜子湖区白鹤种群数量较少 (10 只左右), 偶 见于团结大圩一双兴村的草本沼泽和先让村的东风 圩一三角圩等地. 菜子湖区东方白鹳种群数量在 23 263 只范围内波动, 主要分布于石会村、先让村、塔嘴 村以及白兔湖北部的团结大圩一双兴村一带的草本 沼泽和泥滩地. 在车富村、塔嘴村、珠檀村和嬉子湖 的高赛村附近的滩涂和也有少量分布. 小天鹅在菜 子湖区主要的栖息和受食范围为近岸的浅水区,在 周边的浅滩也偶有分布. 主要分布区在小龙山村、团 结大圩、先让村等地, 在车富村、高赛村等地也有少 量种群分布. 白琵鹭在菜子湖区主要的栖息和受食 范围为近岸的浅水区及围埂上. 主要分布于先让村 和马安村、车富村、松山、塔嘴村等地, 也有少量种群
表 3 菜子湖长系列水位中枯水期月 水位大于 $8.1 \mathrm{~m}$ 和 $8.6 \mathrm{~m}$ 机率分析

Tab.3 Probability analysis of the monthly water level in the dry season of Lake Caizi that is more than $8.1 \mathrm{~m}$ and $8.6 \mathrm{~m}$ of the long-time water level series

\begin{tabular}{ccccc}
\hline \multirow{2}{*}{ 水位 $/ \mathrm{m}$} & \multicolumn{4}{c}{ 频率 $/ \%$} \\
\cline { 2 - 5 } & 12月 & 1月 & 2 月 & 3月 \\
\hline $8.1 \leqq \mathrm{H}<8.2$ & 0.0 & 0.0 & 0.0 & 1.64 \\
$8.2 \leqq \mathrm{H}<8.3$ & 0.0 & 0.0 & 0.0 & 0.0 \\
$8.3 \leqq \mathrm{H}<8.4$ & 0.0 & 1.64 & 0.0 & 0.0 \\
$8.4 \leqq \mathrm{H}<8.5$ & 0.0 & 0.0 & 0.0 & 1.64 \\
$8.5 \leqq \mathrm{H}<8.6$ & 0.0 & 0.0 & 1.64 & 0.0 \\
$8.6 \leqq \mathrm{H} \leqq 9.1$ & 1.64 & 1.64 & 1.64 & 3.28 \\
\hline
\end{tabular}
分布于嬉子湖的高赛村和菜子湖的石会村. 大白鹗在菜子湖区分布范围很广, 如松山、珠檀、先让、车富以及 团结大圩等地. 鸿雁在菜子湖区主要的栖息生境为浅水区域以及水域交界处的草滩,在泥滩或浅水区中掘 取苦草的地下根茎或者以莎草科的叶、芽及鷊草为食, 也常到团结大圩等收割的稻田中受食. 主要分布于团 结大圩一双兴村、先让一马安村、车富村以及嬉子湖的黄盆村一高赛村一带. 豆雁主要分布在菜子湖区团结大 圩的稻田至双兴村一带的草滩、车富村及其附近的草滩和收割的稻田、先让村到马安村防洪堤内的草滩及 嬉子湖的黄盆村至高赛村附近.

冬候鸟越冬期菜子湖泥滩地和草本沼泽出露, 滩涂湿生植被得以发育 (优势种为陌上菅, 主要伴生种有 肉根毛茛和朝天委陵菜), 为水鸟提供了重要的栖息地和受食地. 滩涂和水域豚取和挖掘的水鸟涉及到涉禽 和游禽 2 个生态类型的众多鸟类,包括白头鹤、东方白鹳、苍鹗、大白鹭、鸿雁、豆雁、白琵鹭、小天鹅等. 候鸟 越冬期菜子湖泥滩地和草本沼泽面积与水位之间均具有极显著的负相关. “引江济淮” 工程建设运行后, 规 划水平年 2030 和 2040 年, 多年平均情况下, 菜子湖候鸟越冬期 (12 月一次年 3 月) 水位相比现状分别增加 $0.52 \mathrm{~m}$ 和 $1.12 \mathrm{~m}$, 候鸟越冬期部分适宜生境水深增加,将会加大白头鹤、白鹤、东方白鹳等重要越冬水鸟受 食难度. 规划水平年 2030 年水位上升到 $7.5 \mathrm{~m}$ 时, 菜子湖将减少约 $13.7 \%$ 和 $5.5 \%$ 的泥滩地和草本沼泽湿地. 规划水平年 2040 年水位上升到 $8.1 \mathrm{~m}$ 时,菜子湖将减少约 $16.8 \%$ 和 $10.0 \%$ 的泥滩地和草本沼泽湿地. 水位 进一步上升到 $8.6 \mathrm{~m}$ 以上时, 菜子湖将减少约 $30.4 \%$ 和 $22.2 \%$ 的泥滩地和草本沼泽湿地. 泥滩和草本沼泽湿 地的减少, 造成白头鹤、白鹤、东方白鹳、白琵鹭、大白鹭等重要冬候鸟栖息和受食范围缩小, 影响其栖息和 受食.

从淹没面积上来说, 候鸟越冬期水位长期维持在 $8.6 \mathrm{~m}$ 及以上, 将造成较大面积和比例的泥滩湿地和草 本沼泽湿地淹没, 滩涂湿生植被生长和发育受到影响, 对越冬候鸟的栖息环境及食物源和食物可及性产生 不利影响, 尤其是影响到挖掘啄取集团和浅水取食集团的越冬水鸟, 不利于越冬候鸟生境的保护. 但对于 $7.5 \mathrm{~m}$ 和 $8.1 \mathrm{~m}$ 水位来说,其淹没面积和比例相对较小,但水位长期维持在 $7.5 \mathrm{~m}$ 和 $8.1 \mathrm{~m}$,会影响水位的波 动过程, 增加冬候鸟受食的难度. 鉴于历史上超过 $8.1 \mathrm{~m}$ 的水位出现机率极小, 而且近 30 年未出现水位大于 $8.1 \mathrm{~m}$ 的情况,缺乏可对比数据定量化分析水位上升到 $8.1 \mathrm{~m}$ 以上时对冬候鸟生境造成的具体影响.

根据趋势分析结果, 候鸟越冬期各月水位均表现为显著或极显著的增加趋势, 但近 60 年水位变幅总体 上仅 $0.28 \sim 0.36 \mathrm{~m}$. 按此趋势对 2030 和 2040 年菜子湖水位进行预测, 水位相比现状将抬升不到 0.08 和 0.12 m. 引江济淮工程调度运行后, 规划水平年 2030 和 2040 年, 候鸟越冬期菜子湖水位相比现状分别抬升约 0.52 和 $1.12 \mathrm{~m}$. 因此, 工程调度运行会造成水位相比菜子湖正常水位波动有一定程度的抬升. 虽然菜子湖冬 候鸟越冬期的历史水位也出现过大于 $8.1 \mathrm{~m}$ 的情况, 但其对菜子湖湿地生态水文过程的影响均为短期干扰. 鉴于目前缺乏客观数据和研究成果表明菜子湖水位上升到超过 $8.1 \mathrm{~m}$ 时会对水鸟适宜生境及菜子湖生态承 载能力造成不可逆影响, 而且菜子湖水位在逐渐抬升到 7.5 和 $8.1 \mathrm{~m}$ 的过程中, 是否会形成新的适宜生境也 
存在较大的不确定性. 建议加强菜子湖候鸟越冬期生境适应性调度试验研究及生态环境监测,进一步掌握 菜子湖越冬候鸟适宜生境及重要越冬水鸟种群数量和分布格局对水位变化的响应, 用科学试验和生态环境 监测数据来指导水利工程建设过程中生态保护措施的落实, 创新水利工程建设环境保护措施以科学研究和 基础数据为基础、落实水利工程建设的绿色发展理念.

\section{5 结论}

“引江济淮” 工程调度运行后, 工程调度运行会对菜子湖生态水文过程产生一定影响. 候鸟越冬期菜子 湖水位从 $6.97 \mathrm{~m}$ 上升到 $8.6 \mathrm{~m}$ 时, 菜子湖泥滩地和草本沼泽出露面积不断减少, 滩涂湿生植被生长和发育 受到影响, 越冬候鸟适宜生境总面积和范围不断萎缩, 对越冬候鸟的栖息和受食产生不利影响, 尤其是影响 挖掘豚取集团和浅水取食集团的越冬水鸟的群落结构. 本文为模拟不同水位对菜子湖主要湿地类型及面积 的影响及菜子湖水位优化调度提供了科学依据, 但在阐述湿地类型面积和生境的关系等方面仍存在一定的 局限性. 建议加强菜子湖候鸟越冬期生境适应性调度试验研究及生态环境监测, 分析水位变化对湿地类型 和湿地景观的影响, 并重点分析湿地类型和湿地景观变化对湿地植被动态变化的影响, 以此为基础深人分 析水位变化一湿地生境一湿地水鸟的相互关系, 用科学试验和生态环境监测数据为菜子湖水位进一步优化 调度提供科学依据.

\section{6 参考文献}

[ 1 ] Gao P, Zhou ZZ, Ma SY et al. Vegetation distribution pattern and community succession in the transition from macrophyteto phytoplankton-dominated state in shallow lakes, a case study of Lake Caizi in Anhui Province. J Lake Sci, 2011, 23 (1) : 13-20. DOI: 10.18307/2011.0103. [ 高攀, 周忠泽, 马淑勇等. 浅水湖泊植被分布格局及草-藻型生态系统转 化过程中植物群落演替特征: 安徽菜子湖案例. 湖泊科学, 2011, 23(1): 13-20.]

[ 2 ] Chen JY, Zhou LZ, Zhou B et al. Seasonal dynamics of wintering waterbirds in two shallow lakes along Yangtze Rvier in Anhui Province. Zoological Research, 2011, 32(5) : 540-548.

[ 3 ] Zhu WZ, Zhou LZ. Biodiversity and conservation in Anqing floodplain wetlands. Hefei: Hefei University of Technology Press, 2010. [ 朱文中, 周立志. 安庆沿江湖泊湿地生物多样性及其保护与管理. 合肥: 合肥工业大学出版 社, 2010.]

[ 4 ] Qi SH, Zhang QM, Jiang F et al. Study on the effects on the landscape spatial pattern of the wintering birds' habitat from lake level in Poyang Lake wetland. Journal of Natural Resources, 2014, 29(8): 1345-1355. [齐述华, 张起明, 江丰等. 水位对鄱阳湖湿地越冬候鸟生境景观格局的影响研究. 自然资源学报, 2014, 29(8): 1345-1355.]

[ 5 ] Zhou X, Zhao YS, Liang WG. Modeling of water level and submersion or emerision in Poyang Lake wetland. Geographical Research, 2009, 28(6): 1722-1730. [周霞, 赵英时, 梁文广. 鄱阳湖湿地水位与洲滩淹露模型构建. 地理研究, $2009,28(6): 1722-1730$.

[ 6 ] Xia SX, Yu XB, Fan N. The wintering habitats of migrant birds and their relationship with water level in Poyang Lake, China. Recources Science, 2010, 32(11): 2072-2078. [夏少霞, 于秀波, 范娜. 鄱阳湖越冬季候鸟栖息地面积与水 位变化的关系. 资源科学, 2010, 32(11) : 2072-2078.]

[ 7 ] Yao X, Yang GS, Wang RR. Impact of water level change on wetland vegetation of rivers and lakes. J Lake Sci, 2014, 26 (6) : 813-821. DOI: 10.18307/2014.0601. [姚金金, 杨桂山, 万荣荣等. 水位变化对河流、湖泊湿地植被的影响. 湖泊 科学, $2014,26(6): 813-821$.]

[ 8 ] Kendall MG ed. Rank Correlation Methods. London: Griffin, 1995.

[ 9 ] Mann HB. Nonparametric tests against trend. Econometrica, 1945, 13(3) : 245-249.

[10] Yue S, Pilon P. Power of the Mann-Kendall and Spearman's rho tests for detecting monotonic trends in hydrological series. Journal of Hydrology, 2002, 259(1) : 254-271.

[11] Liu CL, Tan YJ, Lin LS et al. The wetland water level process and habitat of migratory birds in Lake Poyang. J Lake Sci, 2011, 23(1): 129-135. DOI: 10.18307/2011.0119. [刘成林, 谭胤静, 林联盛等. 鄱阳湖水位变化对候鸟栖息地的 影响. 湖泊科学, $2011,23(1): 129-135$.

[12] Hu ZP, Ge G, Liu CL et al. Structure of Poyang Lake wetland plants ecosystem and influence of lake water level for the 
structure. Resources and Environment in the Yangtze Basin, 2010, 19(6): 597-605. [胡振鹏, 葛刚, 刘成林等. 鄱阳湖 湿地植物生态系统结构及湖水位对其影响研究. 长江流域资源与环境, 2010, 19(6)：597-605.]

[13] Mao ZP, Peng WQ, Wang SY et al. Study on effects of water level variation of the Sanmenxia Reservior on wetland hydrological processes. Journal of China Institute of Water Resources and Hydropower Research, 2006, 4(1): 36-41. [毛战坡, 彭文启, 王世岩等. 三门峡水库运行水位对湿地水文过程影响研究. 中国水利水电科学研究院学报, 2006, 4(1): 36-41.]

[14] Wan HX, Sun ZD, Wang R. Influence of water level change of Bosten Lake on wetland eco-environment. Journal of Natural Resources, 2008, 21(2) : 260-266. [万洪秀, 孙占东, 王润. 博斯腾湖水位变动对湿地生态环境的影响. 自然资 源学报, 2008, 21(2): 260-266.]

[15] Hu ZP. The habitat characteristics of White Cranes to live through the winter in Poyang Lake and the recreation for water level changing in the lake. Jiangxi Science, 2012, 30(1) : 30-35, 120. [胡振鹏. 白鹤在鄱阳湖越冬生境特性及其对 湖水位变化的响应. 江西科学, $2012, \mathbf{3 0}(1): 30-35,120$.

[16] Lin GJ, Li ZJ, Lei MJ et al. Response of land cover in Dongting Lake to water level change of Yangtze River. Yangtze Riv$e r, 2015,46(19):$ 114-118. [林国俊, 李志军, 雷明军等. 洞庭湖区土地覆被对长江水位变化的响应分析. 人民长 江, 2015, 46(19) : 114-118.] 